Supplement of Atmos. Chem. Phys., 19, 1971-1983, 2019

https://doi.org/10.5194/acp-19-1971-2019-supplement

(C) Author(s) 2019. This work is distributed under

the Creative Commons Attribution 4.0 License.

(c) (1)

Supplement of

\title{
A proxy for atmospheric daytime gaseous sulfuric acid concentration in urban Beijing
}

Yiqun Lu et al.

Correspondence to: Lin Wang (lin_wang@ fudan.edu.cn)

The copyright of individual parts of the supplement might differ from the CC BY 4.0 License. 


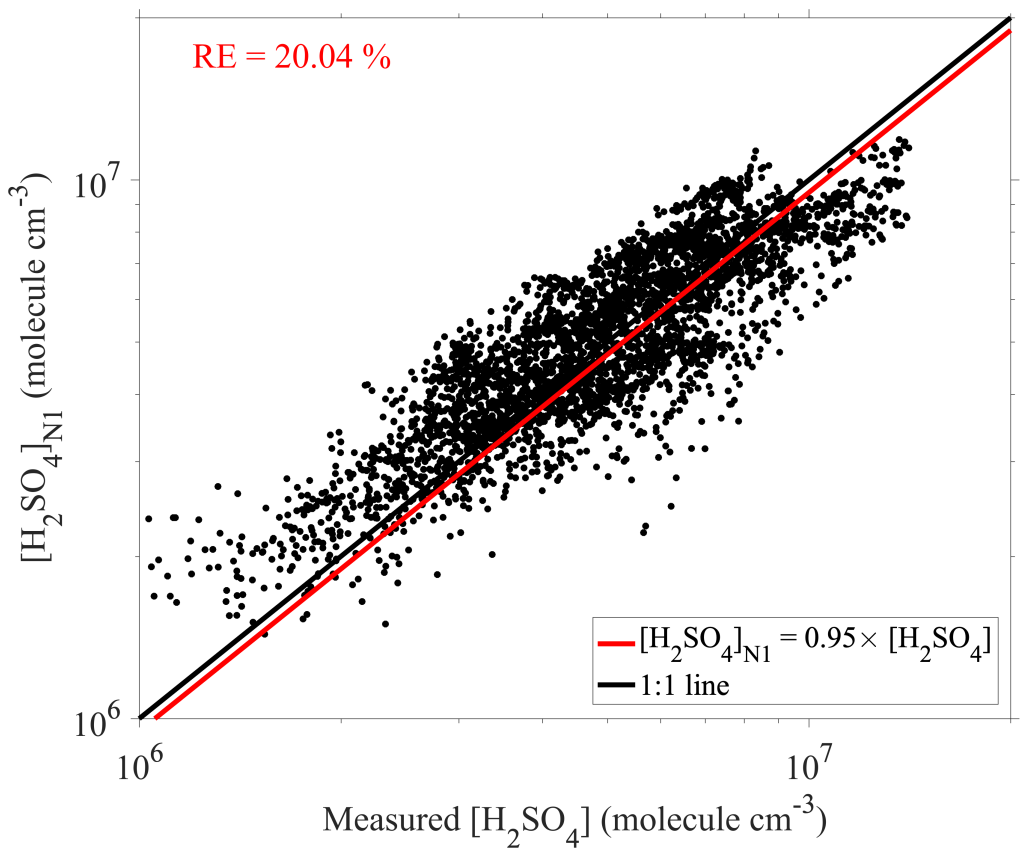

Figure S1a

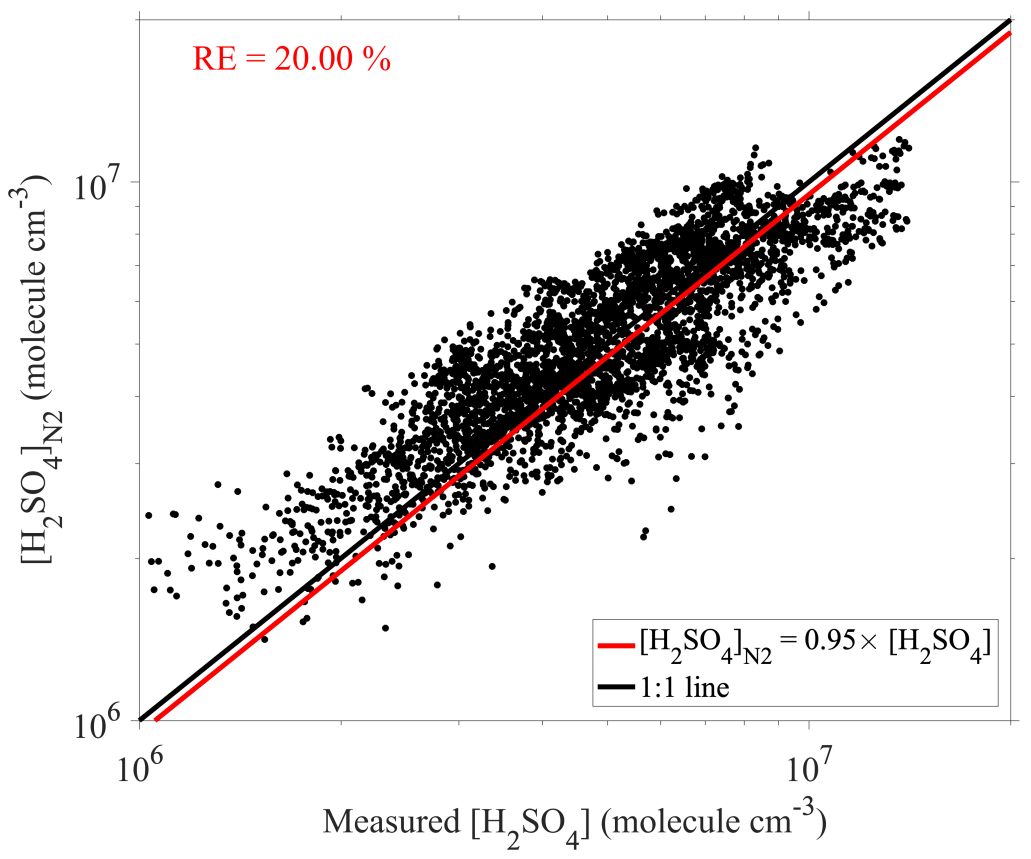

Figure S1b 


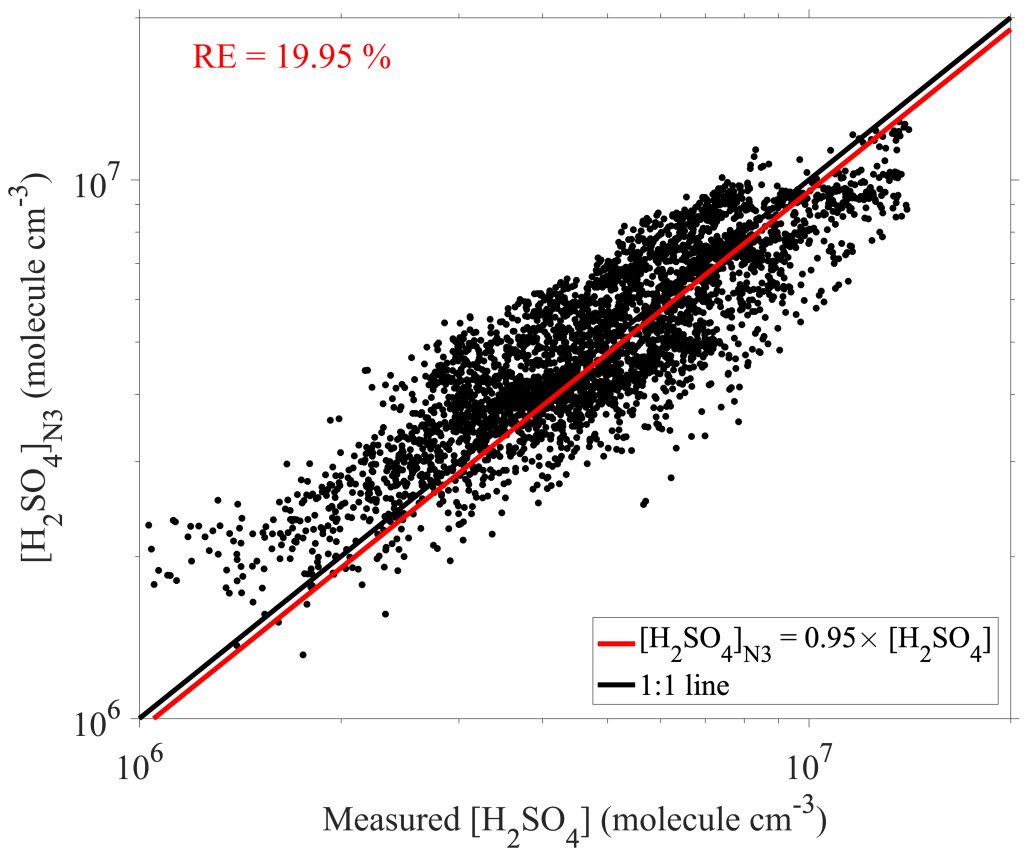

Figure S1c

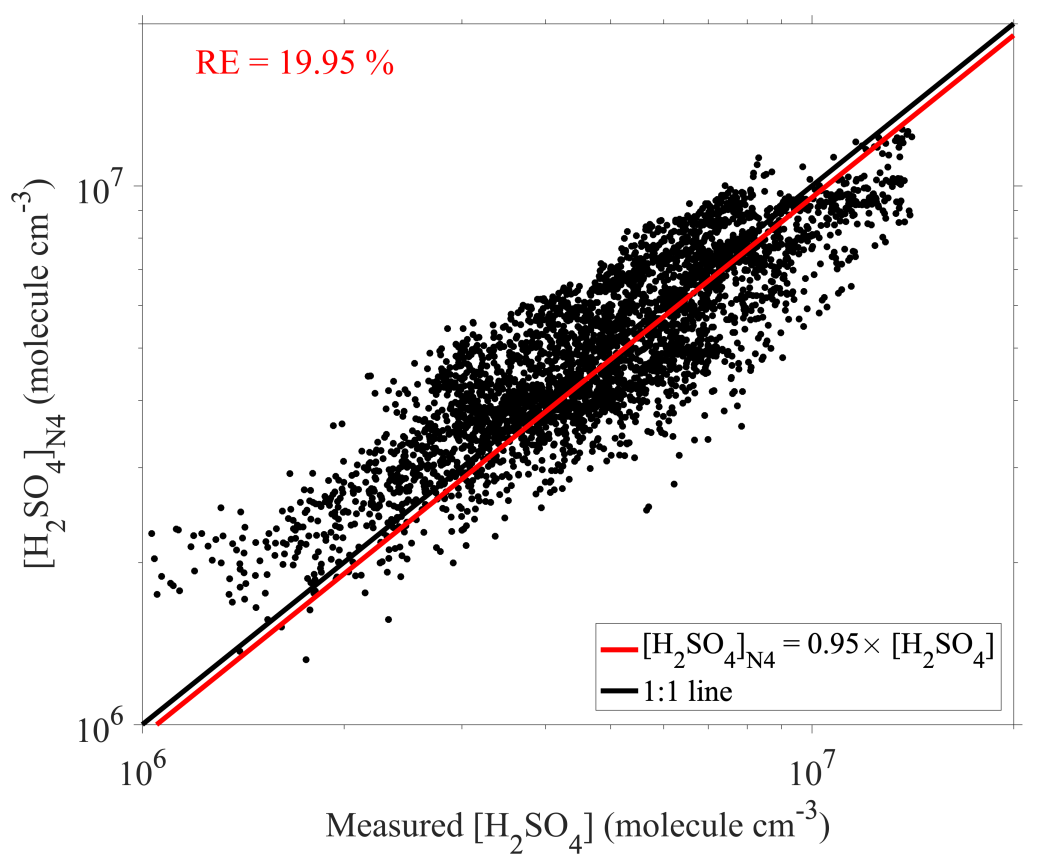

Figure S1d 


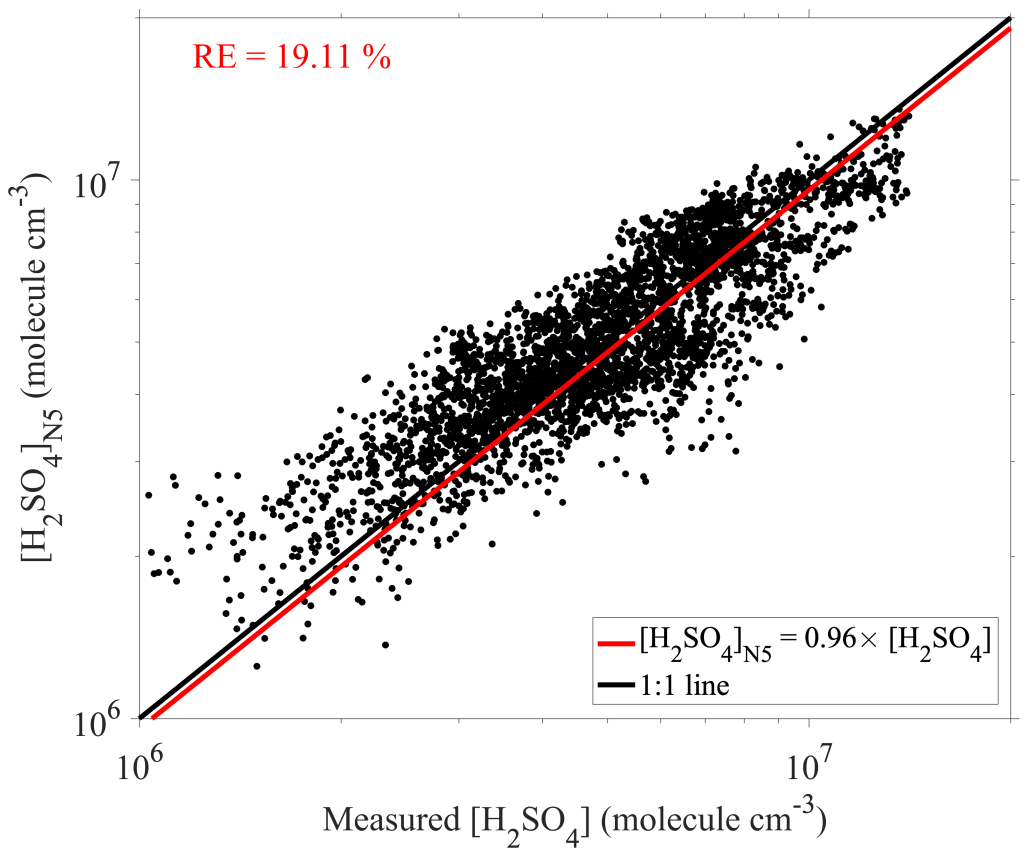

Figure S1e

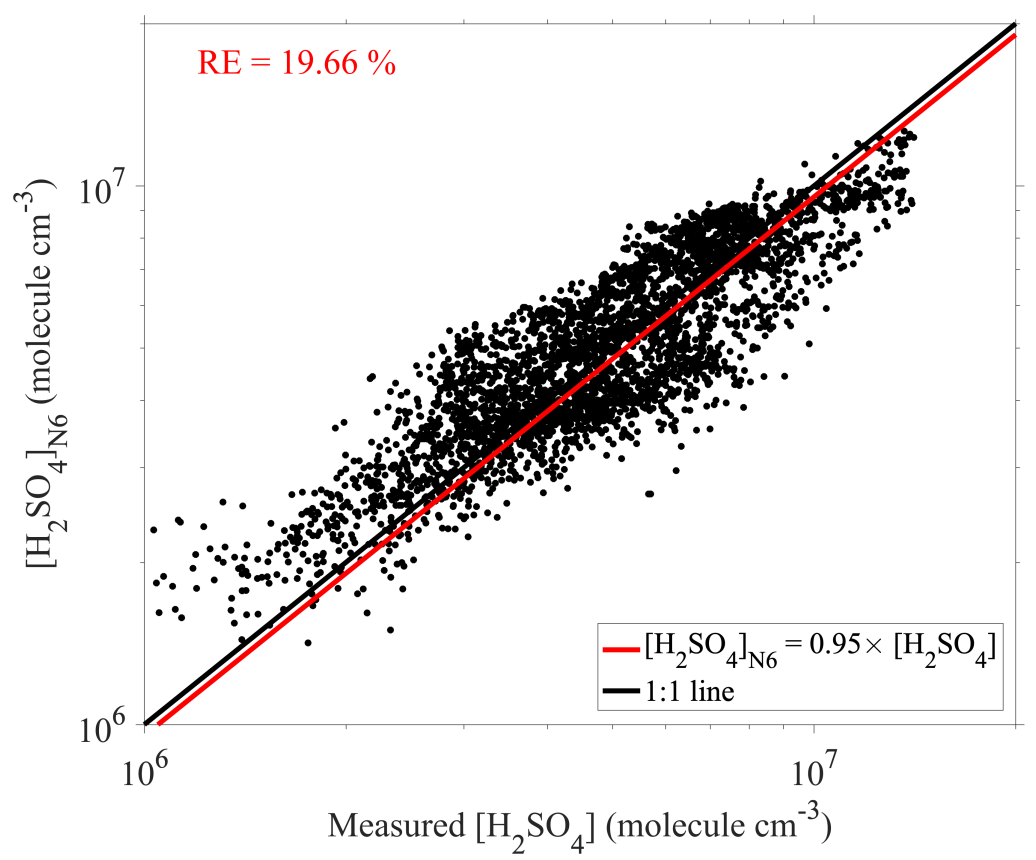

Figure S1f 


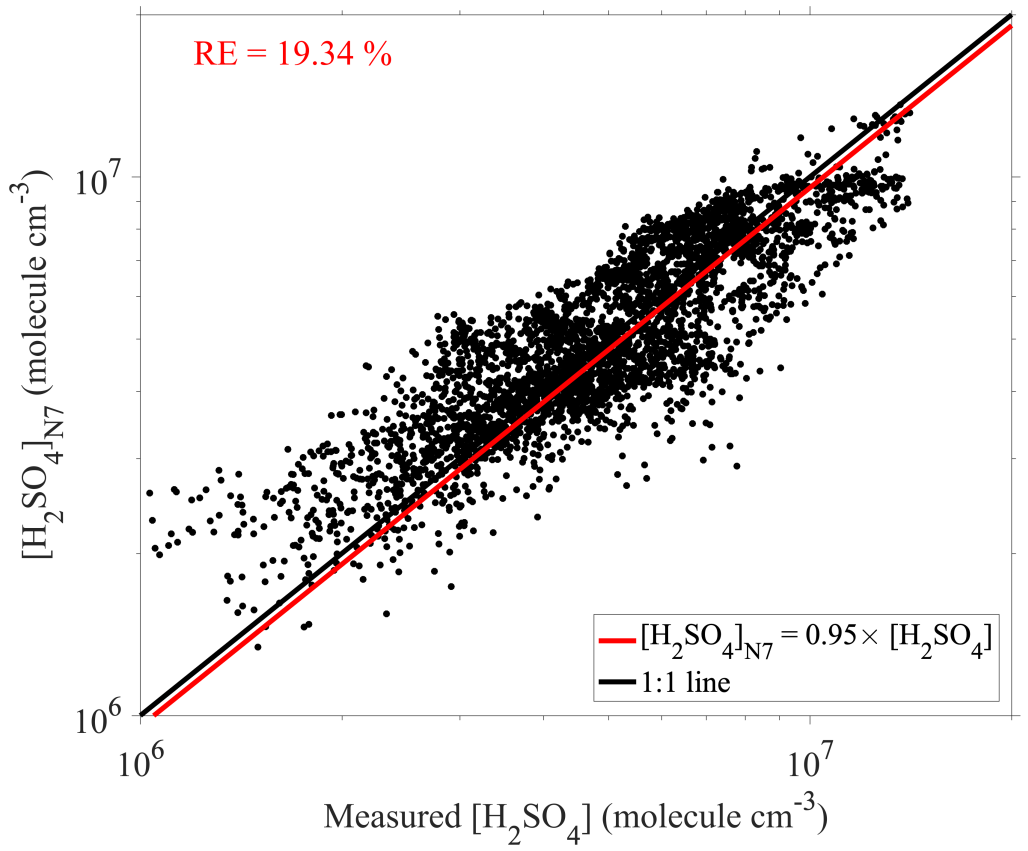

Figure S1g

Figure S1. (a-g) Correlations between measured $\left[\mathrm{H}_{2} \mathrm{SO}_{4}\right]$ and predicted values given by proxies N1-N7, respectively. The black line represents a 1:1 plot. The red line represents a linear fit between $\left[\mathrm{H}_{2} \mathrm{SO}_{4}\right]_{\mathrm{N} i}$ and measured $\left[\mathrm{H}_{2} \mathrm{SO}_{4}\right]$ with a zero intercept. 